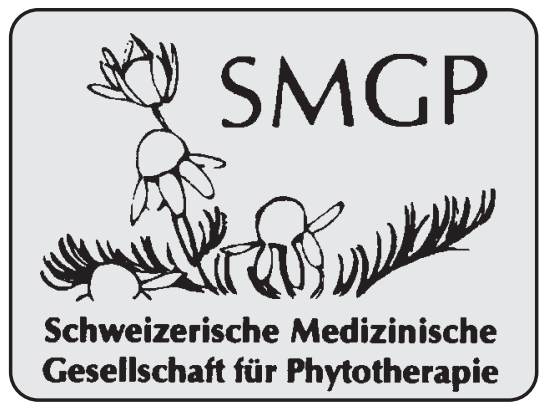

\section{Introduction}

Our society is a collective member of the European Scientific Cooperative for Phytotherapy ESCOP: ESCOP was founded in June 1989 as an umbrella organization representing national phytotherapy associations across Europe, especially in their discussions with European medicines regulators. Since 1996 it has been a company limited by guarantee in the United Kingdom. ESCOP publishes monographs on medicinal plants, which have become an important tool for the registration of phytomedicines. The SMGP/SSPM has two delegates at ESCOP, Dr. Mareike Frater and Dr. Norbert Linnenbrink, who participate in the compilation of the monographs.

\section{The ESCOP Monographs}

ESCOP Monographs have been published for the first time on the occasion of the 1st International ESCOP Symposium 1990 in Brussels (Frangulae cortex, Matricariae flos, Sennae folium, Sennae fructus, and Valerianae radix). These monographs had a similar structure as the monographs of Commission E of the German health authority BGA but they were more extensive, comprising reference lists which proved to be like a gold mine of recent scientific literature on the respective medicinal plant. The EC chief executive for the pharmaceutical sector, Fernand Sauer, one of the architects of the rules governing medicinal products in the European Community, appreciated the ESCOP Monographs and emphasized the scientific character of ESCOP's mission.

Further monographs were published in regular intervals (1992, 1994, 1996, 1997,

\title{
Gesellschaftsmitteilungen - Society Bulletins
}

Forsch Komplementärmed Klass Naturheilkd 2003;10:348

and 1999), from 1994 on in accordance with the new EC guideline on SPC (Summary of Product Characteristics).

ESCOP has now published a book which comprises 80 monographs in SPC format and thus has achieved two major aims:

- update of all monographs, particularly by integration of new scientific publications

- publication of a number of new monographs on plants of major interest such as Cimicifuga racemosa, Ginkgo biloba, Panax ginseng, Piper methysticum (kava-kava), Serenoa repens (sabal), Tanacetum parthenium (feverfew) and Vitex agnus-castus.

Harmonization of the scientific assessment of herbal medicinal products in Europe has always been one of ESCOP's major aspirations. Since its foundation, ESCOP has therefore struggled to obtain acknowledgement of herbal medicinal products in the European legislation.

The European Commission published in May 1994 Core-SPCs for frangula bark, senna leaves and senna fruits, which had been adopted by the CPMP (Committee for Proprietary Medicinal Products), the most important expert committee for medicinal products in the European Community. This marked the beginning of a debate in which all interested parties may participate, but which in the long run is mainly a dialogue between ESCOP and the responsible body in the EC administration, which since some years is the Herbal Medicinal Products Working Party (HMPWP) of the European Medicinal Products Evaluation Agency (EMEA).

It was in 1993 when the European Commission replied amongst others with the following statement to a question on the status of herbal medicinal products from the European Parliament: 'In liaison with the CPMP, the Commission consults Member States, industry representatives and other interested parties on all draft requirements and guidelines. The Commission welcomed the opportunity to work with ESCOP, which is well-established as the European association of national associations for plant medicines, comprising experts from academia and from manufacturers of herbal remedies.'

The most important characteristics of ESCOP Monographs are:

- Format in accordance with the EC guideline 'Summary of Product Characteristics'.

- All important statements are referenced and the cited references are an exhaustive reflection of the currently available scientific literature regarding the respective medicinal plant.

Regarding the status of ESCOP Monographs, the following conclusions can be drawn:

1. Standard for the drug information $\underline{\text { texts }}$

ESCOP Monographs can be considered a standard for statements which are based on good evidence and thus are valid, as well as a standard regarding statements which are not justified and thus not acceptable.

2. Database for the currently available scientific literature

ESCOP Monographs comprise detailed references, qualified for the relevant subject, from the currently available scientific literature on the respective medicinal plant. They are therefore an important base for bibliographic dossiers.

Further information about ESCOP and the newly published monographs (incl. order form) can be found in ESCOP's Internet homepage: www.escop.com.

Dr. Norbert Linnenbrink

\section{KARGER}

두 2003 S. Karger GmbH, Freiburg

Fax +49761 452071 